\title{
O Psicólogo no CRAS: Uma Cartografia dos Territórios Subjetivos $^{1}$
}

\author{
The Psychologist at the CRAS: \\ A Cartography of Subjective Territories
}

El Psicólogo en el CRAS: Una Cartografía de los Territorios Subjetivos
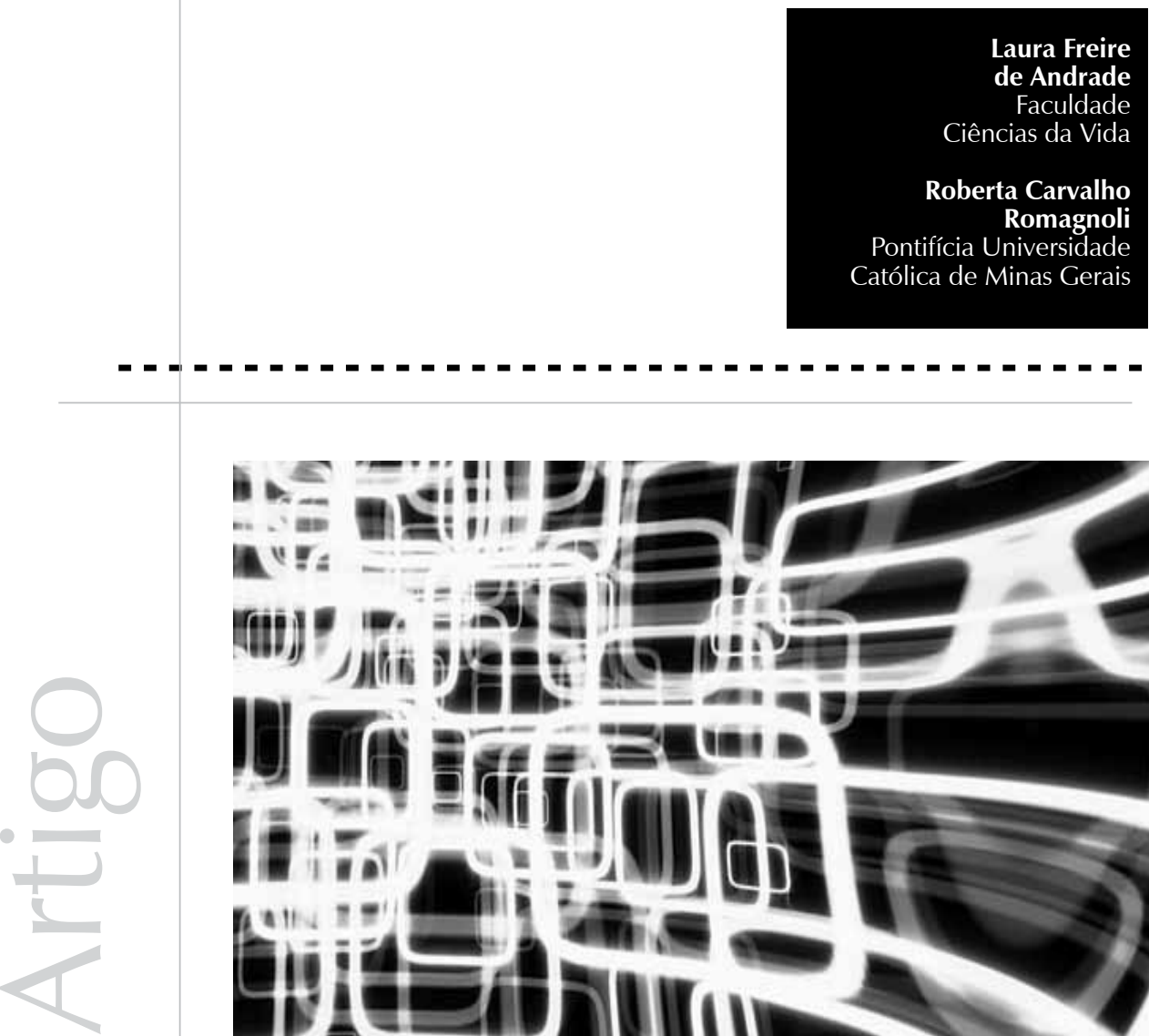

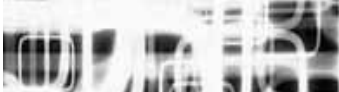

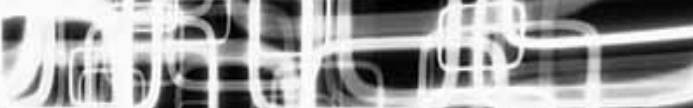
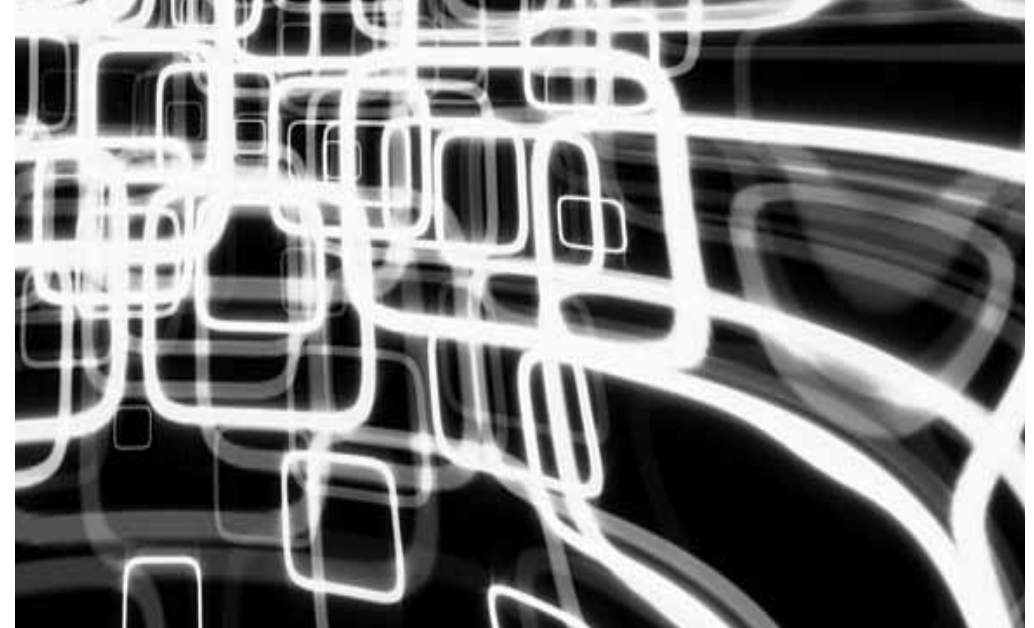
Resumo: Esta pesquisa tem como objeto de estudo as relações subjetivas que emergem entre os psicólogos do CRAS de uma cidade do interior de Minas Gerais e entre os demais profissionais e a comunidade. O objetivo é identificar os pontos de represamento e os de invenção produzidos nessas relações, norteados pela filosofia da diferença e pelo método cartográfico. Foram realizadas entrevistas semi-estruturadas com a equipe e os usuários do CRAS, além da observação participante e do envolvimento da pesquisadora. As relações de poder, as diferenças e as conexões entre as categorias profissionais, os impasses e os desafios para a Psicologia nessa recente unidade pública tornaram-se os territórios explorados ao longo da pesquisa. Os efeitos analisados no trabalho mostram os movimentos ora de intercessão entre a equipe e os usuários, ora de especificidades de cada saber, experimentados tanto pelos profissionais quanto pela comunidade assistida. Além disso, concluímos que tanto o enrijecimento da visão de família nuclear como modelo para as intervenções como os atravessamentos de políticos e profissionais de outras organizações nas atividades cotidianas do CRAS muitas vezes inviabilizam o trabalho proposto. Por fim, percebemos a necessidade de intervenções psicológicas para além da psicologização e do modelo tradicional desse fazer.

Palavras-chave: CRAS. Cartografia. Subjetivação. Área de atuação profissional. Psicólogos.

Abstrac: This thesis conducted a study of the subjective relationships that are present among the psychologists of the CRAS of a small town in Minas Gerais and the other employees as well as the community. The goal is to identify the impoundment and the invention points that are produced in that relationship orientated by the philosophy of difference approach and by the cartographic method. Therefore semistructured interviews with staff and users of CRAS were used, as well as the participant observation and the commitment of the researcher. The power relationships, the differences and connections among the professional categories involved, the obstacles and challenges that concern psychology at this recent public unit became the subject explored during the research. The effects observed during the research show movements of intercession among the staff and the users and also movements of knowledge specificities, experienced by the professionals as well as by the assisted community. Beyond that, we concluded that both the stiffening of the vision of the nuclear family as a model for interventions and the crossings of politicians and professionals from other organizations in the daily activities of CRAS many times made the proposed work impracticable. At last, we noticed the need of psychological interventions beyond the psychologizing and the traditional model of this work.

Keywords: CRAS. Cartography. Subjectivation. Professional Practice Location. Psychologists.

Resumen: Esta pesquisa tiene como objeto de estudio las relaciones subjetivas que emergen entre los psicólogos del CRAS de una ciudad del interior de Minas Gerais y entre los demás profesionales y la comunidad. El objetivo es identificar los puntos de represamiento y los de invención producidos en esas relaciones, norteados por la filosofía de la diferencia y por el método cartográfico. Fueron realizadas entrevistas semi-estructuradas con el equipo y los usuarios del CRAS, además de la observación participante y del envolvimiento de la pesquisidora. Las relaciones de poder, las diferencias y las conexiones entre las categorías profesionales, los impases y los desafíos para la Psicología en esa reciente unidad pública se tornaron los territorios explorados a lo largo de la pesquisa. Los efectos analizados en el trabajo muestran los movimientos ora de intercesión entre el equipo y los usuarios, ora de especificidades de cada saber, experimentados tanto por los profesionales como por la comunidad asistida. Además de eso, concluimos que tanto el endurecimiento de la visión de familia nuclear como modelo para las intervenciones como los atravesamientos de políticos y profesionales de otras organizaciones en las actividades cotidianas del CRAS muchas veces inviabilizan el trabajo propuesto. Por fin, percibimos la necesidad de intervenciones psicológicas para además de la psicologización y del modelo tradicional de ese hacer.

Palabras clave: CRAS. Cartografía. Subjetivación. Ubicación de la Práctica Profesional. Psicólogos.

${ }^{1}$ Pesquisa

financiada pela

FAPEMIG.

\section{A Política Pública da Assistência Social visa} a garantir a todos os que dela necessitarem, sem contribuição prévia, a proteção social. A concepção da assistência social como política e como direito à proteção e à seguridade social através da Constituição de 1988 trouxe uma nova abordagem a essa política, objetivando desvinculá-la dos tradicionais modelos assistencialistas e compreendendo-a como garantidora dos direitos da cidadania (Brasil, 1988). Sendo um direito do cidadão, pretende prover os mínimos direitos sociais para garantir as necessidades básicas, a segurança de sobrevivência (rendimento e autonomia), a segurança da acolhida (alimentação, 
vestuário e abrigo) e o convívio familiar. Suas diretrizes baseiam-se na descentralização das ações, sendo de responsabilidade da esfera federal a coordenação e as normas gerais, e dos Estados e Municípios a coordenação e a execução dos programas e projetos, garantindo-se o comando das ações em cada esfera de governo e respeitando-se as diferenças e as características territoriais locais. O Sistema Único da Assistência Social (SUAS), implantado em 2005, no País, define e organiza toda a referida política, reordenando a gestão, visando a ações descentralizadas e participativas em todo o Brasil (Ministério do Desenvolvimento Social e Combate à Fome, 2006). O SUAS estabelece ainda duas formas de proteção social, que se ocupam das vulnerabilidades e riscos que os cidadãos enfrentam em sua trajetória de vida. A proteção social básica e a proteção social especial compõem essas duas formas, sendo a primeira responsável por prevenir situações de risco, e a segunda, já intervindo em casos em que há situações de risco com ou sem rompimento dos vínculos familiares.

O Centro de Referência da Assistência Social (CRAS) é um equipamento público que se enquadra na proteção social básica e que atua na perspectiva de prevenção de situações de risco. O CRAS fica localizado, obrigatoriamente, em territórios onde há presença de vulnerabilidades e riscos sociais, enfocando a família e os vínculos comunitários (Ministério do Desenvolvimento Social e Combate à Fome, 2006). Essa unidade é a responsável pela execução de serviços, programas e projetos que potencializam a família como unidade de referência, reconhecendo os diversos arranjos familiares, valorizando as particularidades de cada grupo familiar, fortalecendo esses vínculos e articulando-os com seu contexto comunitário. O CRAS, como proposta de unidade de atenção social básica, é composto por psicólogos, assistentes sociais, coordenador, auxiliar administrativo e educadores sociais, entre outros. Em 2003, inicia-se a implantação dessas unidades públicas em 301 Municípios brasileiros, dos quais a cidade pesquisada, no Estado de Minas Gerais, é uma das pioneiras.

Duas mil quatrocentas e cinquenta e quatro pessoas habitam esse Município mineiro (Instituto Brasileiro de Geografia e Estatística [IBGE], 2000). O CRAS pesquisado possui trezentos e oitenta e quatro famílias cadastradas e acompanhadas pela equipe técnica. Os projetos desenvolvidos atualmente são: Projeto Cantina da Cidadania, que visa a atender pessoas desnutridas, malnutridas e/ ou acamadas, bem como obesos, hipertensos, diabéticos, alcoolistas e pessoas com câncer; seu objetivo é garantir a esses usuários nutrição que propicie repor ou complementar a alimentação diária, melhorar o quadro clínico e a qualidade de vida; Projeto Fiando e Desfiando a Vida: oficina para manufatura de panos de prato e congêneres, como mecanismo de geração de renda de famílias na linha de pobreza; Projeto Centro de Intermediação para o Trabalho: para os jovens maiores de 16 anos e adultos excluídos do processo de trabalho e renda, esse projeto visa a proporcionar capacitação para mão de obra desocupada e/ou desempregada; Projeto Dançando para o Futuro: oficinas de dança e capoeira para crianças a partir de sete anos, adolescentes e terceira idade; o objetivo é estimular a autoestima, a melhoria da qualidade de vida, a exteriorização das emoções e a ampliação do convívio social; Telecentro: seu objetivo é a inclusão digital de toda a população local; Projovem Adolescente: serviço do Governo Federal que atende jovens entre 15 e 17 anos. Os objetivos são a permanência ou o retorno à escola, a assistência às famílias dos participantes e a 
prevenção de situações de risco. Para isso, são realizadas ações socioeducativas como esporte, cultura, formação inicial para o trabalho e ações comunitárias. Outros dois projetos são a feirinha e a parceria com a Empresa de Assistência Técnica e Extensão Rural de Minas Gerais (EMATER). A feirinha tem o objetivo de divulgar e vender os produtos confeccionados no CRAS, e parte da produção de legumes e verduras da EMATER fica destinada aos usuários que necessitam desse auxílio.

\section{Como pesquisar: o olhar da filosofia da diferença e os processos de subjetivação}

No contexto apresentado acima, realizamos uma cartografia para rastrear a realidade e os encontros subjetivos presentes no cotidiano de trabalho dessa unidade. A pesquisa foi realizada através de entrevistas semiestruturadas com os psicólogos, técnicos e usuários do CRAS estudado. Essas entrevistas ocorreram nos meses de janeiro, março, setembro e novembro de 2008. Durante as visitas à unidade pesquisada, utilizamos ainda a observação participante e a presença da pesquisadora para cartografar os efeitos dos encontros.

Cartografar significa navegar entre paisagens, capturar intensidades em que se registram os encontros, e não os objetos. A cartografia não pretende ser neutra, uma vez que, nesses encontros, sujeitos e objetos se tornam outros, um terceiro, e assim por diante e infinitamente (Kirst, Giacomel, Ribeiro, Costa, \& Andreoli, 2003). Nessa proposta, o envolvimento do pesquisador é essencial, pois este é usado para mapear as intensidades, as composições e as decomposições dos territórios, desenhando as linhas que se articulam. Essas linhas às vezes são duras, correspondendo ao que está estabelecido e instituído e mantendo os modelos e as formas identitárias, mas também, dependendo das circunstâncias, podem ser flexíveis, produzindo potência de vida, desterritorializações e inaugurando criações instituintes, que trazem o impensado, o inédito.

A cartografia persegue o singular, buscando mapear o transitório, o local, o campo de forças que acompanha determinada situação, visando a abarcar provisoriamente a complexidade que ali atua (Mairesse, 2003). Nesse sentido, a intenção cartográfica se faz na singularidade dos momentos que se atualizam na produção de modos de existência conectados com a pluralidade e com a resistência. Resistir é reverter a apreensão da vida no capital, escapando da lógica dominante de consumo para liberar a potência de vida, a invenção. Há coexistência entre resistir/inventar e reproduzir, por isso, o cartógrafo desenha as forças que mantêm a lógica dominante e as linhas de fuga, arrancando as sensações, produzindo redes de sentidos.

Nesse trajeto, utilizamos o referencial teórico da filosofia da diferença, também chamada de esquizoanálise, que insiste na faceta inumana existente na realidade e que também faz parte da subjetividade. A subjetividade ligada ao sujeito e à interioridade é somente um aspecto da subjetividade que se refere ao "pólo identitário e sedentário" (Schérer, 2005, p. 132). Em uma perspectiva esquizoanalítica, é preciso se livrar desse raciocínio, na busca de entender como o nosso eu mobiliza a produção subjetiva incorporal, migrando os territórios - os que possuímos e os que podemos vir a ser - como sujeitos nômades, dispostos a outros encontros, que estão à espera de navegar por outras trilhas, outros territórios antes desabitados, que corrompem a subjetividade, e dela arranquem elementos fazendo-se um novo local de moradia. Isso é 
"É que nunca temos, nem podemos ter jamais, ideia suficientemente clara desse aglomerado indistinto..., pois um pouco mais de exatidão nos lança num abismo fundo demais, em tudo e por tudo inimaginável" (Borges, 2002, p. 221). a conexão. O que agenciamos? Agenciamos encontros com músicas, com uma estrada, com uma obra de arte, com uma pedra; tudo o que verdadeiramente existe pode tornar nossa subjetividade diferente daquilo que a compunha anteriormente. Esse é um processo transversal e imanente, composto por estratos e fluxos, formas e forças.

Nossa subjetividade é habitada por segmentos, linhas estratificadas e duras, sustentadas por representações que abarcam a classificação do sujeito em raça, gênero, sexo, profissão e classe social, que formam planos de organização estratificados. Essas linhas se mantêm por processos binários, como, por exemplo, homem versus mulher, negro versus branco, usuário versus especialista, comunidade versus profissional. Esses segmentos nos formatam em estratos, territórios, cuja composição é codificada como identidade. O segmento binário compõe as identidades individuais e grupais. De acordo com Deleuze e Guattari (1996), esses segmentos estancam a circulação da vida e operam cortes e recortes que configuram a forma de a espécie humana se colocar no mundo. Os segmentos têm ainda como objetivo estabelecer métodos de hierarquização e de organização.

Além dessas linhas duras, a subjetividade é atravessada por forças e fluxos que possuem outro funcionamento e que escapam à homogeneização, convocando a heterogênese, compondo processos de subjetivação inventivos, planos de consistência que propiciam agenciamentos. Pelo fato de também ser formada por linhas relativamente flexíveis, a subjetividade oscila entre o território já estabelecido - a faceta formal identitária - e as linhas de fuga, que trazem a desterritorialização, o novo. O que ocorre é que as linhas flexíveis nos conectam com uma infinidade de entornos, de fluxos que vêm de fora e que correspondem a uma zona de indeterminação entre as linhas duras e as linhas de fuga. Nas palavras de Márcio Borges, compositor mineiro: "É que nunca temos, nem podemos ter jamais, ideia suficientemente clara desse aglomerado indistinto..., pois um pouco mais de exatidão nos lança num abismo fundo demais, em tudo e por tudo inimaginável" (Borges, 2002, p. 221).

Conforme Deleuze e Guattari (1996), as fissuras no segmento possibilitam a formação de linhas de fugas, que se dão no molecular, mas passam para o molar, para o visível, onde se vê sua efetivação. Essas linhas escapam ao território existencial habitado até então, e produzem uma desterritorialização, para permitir a passagem dos fluxos da vida e derivar em uma criação/invenção. Somos então habitados por uma estranheza, afetados por sensações desconhecidas que se viabilizam em agenciamentos, que nos levam à produção do inédito, sustentando diferenças singulares. Com isso, tornam-se obsoletos os valores subjetivos que antes habitavam a nossa casa, o nosso território identitário. Em outro lugar, reconfigura-se algo inteiramente novo, mas que também se torna recolocado e estabelecido. Essa é a processualidade da vida: habitar um território, ser afetado pela exterioridade de forças inumanas, desterritorializar e novamente territorializar. Esse é o processo de subjetivação, de invenção, ou seja, a subjetividade, em seu território fixado (linhas duras) se abre (linhas flexíveis), e os acontecimentos que emergem dessa abertura produzem novas conexões inventivas (linhas de fuga), convocando-nos a habitar outro território.

Sob o olhar da filosofia da diferença, a realidade é imanência, e não transcendência, lógica hierárquica. Nessa perspectiva, os processos de subjetivação são entendidos 
como o conjunto de instâncias individuais/ sociais e pré-individuais fabricados pelas máquinas sociais, pela mídia, pela linguagem, uma heterogênese de componentes que, através dos agenciamentos, produzem novas formas de subjetivar-se. Os deslocamentos da subjetividade se dão através do que nos afeta de fora, que nos impulsiona e pressiona à ruptura do sentido, corrompendo a nossa subjetividade e levando-a a se abrir e a criar novos sentidos. Essas são a construção e o processo de territorialidade presentes na subjetivação. Tal noção é complexa, pois depende da articulação dinâmica da realidade, no entrecruzamento das diversas instâncias - sociais, químicas, biológicas, arquitetônicas, de poder, corporais, sexuais, étnicas, culturais, tecnológicas, dentre tantas outras - para conjugar/compor/arranjar a produção subjetiva. Trata-se, portanto, de uma multiplicidade de elementos conjugados, de uma emergência do coexistir do estado de coisas em que nos encontramos, a diluição da contradição - não somos isso ou aquilo somos compostos e conjugados pela geografia de estados intensivos, com contornos abertos à construção de novos mapas (Pelbart, 2000).

Essas ideias visam a fazer compreender as relações em atenção aos modos de funcionamento, no modo como os agenciamentos acontecem, como eles produzem e fabricam processos que mantêm o estado das coisas, a reprodução de modelos instituídos e as possibilidades de novas conexões. Romagnoli (2004) assinala a visão da filosofia da diferença sobre a realidade como pura produção. Tudo o que existe é produzido tanto para o novo - inventivo, como para o que já foi produzido e para impedir a produção. Somos produção, reprodução e antiprodução, acontecimentos conjugados simultaneamente nas relações. Vale dizer, então, que criamos, copiamos e estagnamos as coisas, nossos encontros e a nós mesmos, tudo ao mesmo tempo. Esse é o processo subjetivo, que não se reduz somente ao indivíduo e à interioridade mas que diz respeito também à exterioridade e às situações que convocam composição. Tal processo impulsiona o sujeito à criação e a processos de subjetivação inventivos na produção de singularidades nos encontros que emergem no campo do indizível, invisível, mas do que é experimentado, sentido, reconfigurando, assim, os territórios subjetivos.

\section{Rastreando o CRAS: o território e suas linhas (tensões?)}

A partir dessa perspectiva teórica, abordamos o Centro de Referência da Assistência Social (CRAS) no interior de Minas Gerais, cuja equipe possui dois psicólogos, dois assistentes sociais, um coordenador, um nutricionista, um auxiliar administrativo e oito educadores sociais/monitores.

No decorrer do processo da pesquisa, utilizamos os efeitos dos encontros estabelecidos entre a pesquisadora, a equipe e os usuários para realizarmos as considerações sobre os impactos da Psicologia e do CRAS naquela comunidade. Sendo assim, desde o trajeto à cidade, observando a geografia e a história locais, realizando entrevistas com os técnicos e os usuários da unidade pesquisada, acompanhando os profissionais em visitas domiciliares, em conversas informais com moradores e nas interferências políticas, foram todos eles tratados como elementos de problematização do campo, em uma tentativa de manter a coerência com o marco teórico proposto, a filosofia da diferença, e com o método utilizado, a cartografia, examinados acima.

Observamos em nossa pesquisa que o atendimento da equipe CRAS é 
preponderantemente voltado para ações e intervenções postuladas pela assistência social que determina essa unidade como local de acolhimento e encaminhamento da população à rede socioassistencial. Nesse contexto, evidenciamos uma cisão hegemônica em que a comunidade, os profissionais de outras unidades e a própria equipe do CRAS direcionam os atendimentos como psicológicos e assistentes sociais, conduzindo-os aos seus respectivos profissionais. Estabelece-se, portanto, de forma dominante, uma Psicologia caracterizada como saber da psique, e a área social como pertencente ao serviço social, associando-se saúde/doença mentais à Psicologia e dificuldades socioeconômicas ao segundo. Percebemos que nossa profissão é compreendida, em alguns momentos, como saber realizado em um espaço fechado, no setting tradicional do campo psi. Todavia, essa vertente tradicional não se sustenta no cotidiano de trabalho no CRAS.

Sobre a Psicologia no universo estudado, observamos que, em meio a intervenções realizadas por uma equipe multiprofissional através da promoção de saúde, prevenções de situações de risco e visitas domiciliares, convocam-se e são realizadas atuações fora dos consultórios. Com isso, os profissionais são convidados a lançar novos olhares sobre a Psicologia inscrita nos espaços públicos, fruto inclusive da desestabilização a que esses profissionais são arremessados em seu cotidiano de trabalho. Diante desse desafio, constatamos que, nos encontros com servidores públicos, tais como médicos e professores, há certa incompreensão sobre o lugar da Psicologia no CRAS, pois esses ainda entendem a Psicologia como prática liberal e privada, responsável pelo diagnóstico e acompanhamento psicoterápico dos usuários do CRAS. Com base nessas observações, nas entrevistas realizadas e na nossa própria inserção profissional em um CRAS, inferimos que o modelo da prática psi dominante permanece, de maneira geral, atrelado ao projeto de modernidade. Desde seu surgimento, na modernidade, as ciências mostram-se marcadamente especializadas e separadas umas das outras. Nesse sentido, observamos o processo binário e os segmentos da subjetividade presente nas relações, e, em alguns momentos, constatamos a manutenção da compartimentalização dos saberes no cotidiano do CRAS. Sendo assim, é mantida uma visão da Psicologia que atende a modernidade, em seu projeto de ordem e de uma ciência compartimentada em disciplinas especializadas e especializantes, segmentos binários e planos de organização ordenados e segmentados (Hüning \& Guareschi, 2005).

Atendendo o projeto da modernidade, a Psicologia é compreendida, em determinadas circunstâncias, como saber que é realizado em um espaço fechado, no setting tradicional do campo psi. A comunidade e os profissionais de outras unidades governamentais questionam a atuação do psicólogo quando este trabalha sob outra ótica, e não aceitam que o psicólogo não possa diagnosticar, fazer atendimento clínico e criticam a prática não convencional como se isso fosse o que a Psicologia tem a oferecer independentemente da realidade em que sua prática se insere. Essa relutância emerge nas falas dos psicólogos que relatam as dificuldades de atuar em espaços públicos, realizando visitas domiciliares, fazendo intervenções durante aulas e cursos, dentre outros, e atuando fora do modelo tradicional. Nesse sentido, percebemos um saber endurecido em sua forma identitária, composto por linhas duras, concomitantemente à atuação para além do espaço formal da Psicologia.

No cotidiano do CRAS, profissionais se deparam com sujeitos, ambientes e grupos 
complexos. A Psicologia, não raro, se encontra habitada, então, por um abismo entre o saber acadêmico, adquirido na graduação e divulgado em livros e pesquisas, e a realidade vivida no cotidiano, como foi colocado pelos profissionais entrevistados. Em nosso estudo, percebemos que a formação do psicólogo e a realidade brasileira ficam desvinculadas, pois, no âmbito da formação, há uma hegemonia na ênfase clínica voltada para o atendimento às camadas sociais com grande poder aquisitivo, como foi colocado por grande parte dos entrevistados. Cabe ressaltar que, em estudos recentes sobre a atuação do psicólogo no atendimento a crianças e adolescentes em risco, verificase também o discurso e a prática pautados nesse modelo: "Sobressai-se..., na maioria dos dados, a concepção da atuação do psicólogo fundamentada no modelo clínico e individual. A atuação do psicólogo continua, em parte, pautada no modelo técnico, liberal e autônomo" (Alberto, Almeida, Dória, Guedes, Sousa, \& França, 2008, p. 571). O mercado de trabalho, porém, oferece oportunidades em organizações governamentais e não governamentais no atendimento à população pobre, sobretudo através das políticas públicas. Todavia, concebemos que a Psicologia deva primar por uma prática política e libertária em qualquer espaço em que ela se inscreva independentemente da população atendida (Ferreira Neto, 2004).

Concordamos com Benevides de Barros (2005), que aponta a necessidade cada vez mais premente de não se sustentar o isolamento indivíduo versus social e nem a despolitização das práticas clínicas. Para driblar o risco de psicologização dos problemas e o aprimoramento de mecanismos de exclusão social, é preciso, ainda, redimensionar as nossas práticas, questionando a clínica, que se apresenta também como social, que discutiremos abaixo. A clínica deve ser social, ampliada, ampla, que se faz e se refaz em vários territórios, rompendo paradigmas e deflagrando processos de subjetivação inventivos e deslocamentos micropolíticos que trazem o novo (Birman, 2001; Guerra, 2002; Maciel Junior, Kuppermann, \& Tedesco, 2005; Passos \& Benevides de Barros, 2004; Romagnoli, 2006; Romagnoli, Moreira, \& Neves 2007), a clínica feita por vários profissionais, pautada na heterogeneidade - de locais de trabalho, de classes sociais, de espaços distintos, empregando teorias diversas, em encontros singulares.

Por outro lado, o lugar da assistência social é percebido pela comunidade com descrédito, com o desinteresse de governantes e com a troca de favores, bem como local de escuta, apoio e laços sociais. Embora o CRAS pesquisado tenha, sim, ligações macropolíticas com a política municipal interiorana e personalista e esteja capturado em linhas reprodutivas e despotencializadoras, é um programa que também independe de atuações políticas eleitoreiras; dessa maneira, configura um programa de ação continuada e uma política pública reconhecida como direito do cidadão (Ministério do Desenvolvimento Social e Combate à Fome, 2004). De acordo com Demo (1995), é preciso compreender a assistência como parte integrante de cidadania, que possui suas especificidades e não pretende e não deve ser entendida como a resolução de todos os problemas sociais e econômicos. As necessidades básicas da população são múltiplas e não se reduzem à sobrevivência material. A assistência social, para ser efetiva, depende de uma política global integrada que ultrapassa os limites de sua própria política. É importante assinalar que a assistência social se distingue do assistencialismo na medida em que o primeiro corresponde a um direito humano entendido como atendimento emergencial, de forma 
que "se favoreçam atividades de produção e participação" (Demo, 1996, p. 31) no intuito de emancipar o sujeito assistido. Já o assistencialismo é compreendido como assistência que "cultiva o problema social sob a aparência de ajuda, ...é estratégia de manutenção das desigualdades sociais" (Demo, 1996, p. 30). No cotidiano, tudo isso ocorre de forma ativa e processual, escapando, muitas vezes, da lógica na qual somos submetidos e à qual submetemos os usuários. Vejamos como exemplo a questão da distribuição de cestas básicas no CRAS, onde realizamos essa pesquisa. A princípio, esse benefício estaria na lógica assistencialista, que prefeito e técnicos da unidade tentam combater. É certo que a doação de cestas básicas pode ser entendida como prática assistencialista, pois mantém os sujeitos na mesma condição de pobreza em que se encontravam anteriormente à doação. Devemos, portanto, pensar na necessidade de assistir de modo emergencial para se trabalhar, posteriormente, a autonomia e a emancipação dos usuários. São situações que psicólogos e assistentes sociais do CRAS vivem com frequência no cotidiano de seu trabalho. Percebemos que há um movimento imanente de assistencialismo e de busca de autonomia nas intervenções, que produzem questionamentos e discussões entre os profissionais.

Vale salientar que, em nossa pesquisa de campo, ao buscarmos conhecer as singularidades e o cotidiano do CRAS, encontramos especificidades e semelhanças nas práticas profissionais dos psicólogos e assistentes sociais, o que tem provocado efeitos diversificados. Notamos que a equipe do CRAS realiza os atendimentos e acolhimentos dos usuários da mesma maneira, assim como as atividades burocráticas cotidianas são realizadas igualmente pelos técnicos, o que pode se traduzir como um intercessor entre as duas disciplinas - Psicologia e serviço social. Os próprios usuários ora identificam a diferença no atendimento e nas intervenções, ora compreendem que as duas categorias se misturam, sendo demonstrada a coexistência de funcionamentos distintos, que são, em determinadas circunstâncias, definidos e classificados, e que, em outras, traduzem agenciamentos que podem ser produtivos. Entretanto, em alguns momentos, há um direcionamento específico para cada saber. Para a Psicologia, direcionam-se demandas que dizem respeito às questões emocionais e às relações familiares, ficando para o serviço social as questões de encaminhamentos, acesso e orientações sobre direitos, benefícios e documentos, ou seja, cada disciplina impede que a outra se aproxime de seu território, mantendo-se uma afastada da outra, resguardada pelo seu especialismo, seus procedimentos e técnicas. A esse respeito, vimos que, no manual de orientações do CRAS e em recortes de jornais, há certa incongruência quanto às práticas desses profissionais (Afonso, 2008; Conselho Federal de Psicologia, 2006; Conselho Regional de Psicologia de Minas Gerais, 2007; Ministério do Desenvolvimento Social e Combate à Fome, 2006). Ora indica-se que as práticas devem estar relacionadas à interdisciplinaridade - uma relação pactual entre saberes conexos que produzem uma intenção comum, possuindo um eixo hierarquicamente superior que redefine tais saberes - ora aconselha-se que o trabalho no CRAS seja orientado pela transdisciplinaridade - todos os saberes envolvidos abandonam suas identidades em prol da criação de um campo de saber autônomo e próprio, fabricando intercessores entre as disciplinas. Isso significa dizer que tais propostas, além de serem compreendidas como confusas pelos profissionais que ali atuam, constituem também um desafio no dia a dia do serviço. Aliás, na prática, essa 
indistinção dos saberes conduziu, em alguns momentos, na insistência na identidade de cada campo, ao endurecimento da referência corporativa, ao plano de organização, em vez da formação de um território entre as disciplinas, à criação de indagações que as levassem a se agenciar. Em outras palavras, o que se viu foram movimentos de indiferenciação e especificidades tanto da Psicologia quanto do serviço social no cotidiano do CRAS, sendo compostos ora planos de organização estratificados, segmentados, ora planos de composição em que agenciamentos criaram dimensões impensadas.

A história desse CRAS começa com sua implantação, que coincide com ano eleitoral, afetando as relações entre usuários, profissionais e políticos. Na época, havia uma descrença e a desconfiança dos moradores de que o programa permaneceria na cidade caso houvesse a mudança do gestor municipal. Apesar de ser um programa que se mantém independente de prefeitos, governadores ou do Presidente da República, o CRAS vivencia ações descontinuadas atravessadas pela política local, que, muitas vezes, se acham presentes no cotidiano dos profissionais e usuários, reproduzindo relações de poder. As descontinuidades surgem pelo repasse de verba interrompido - que acontece anualmente após a avaliação dos gastos - pela substituição de profissionais, pela fragmentação dos saberes e também pela dificuldade de suporte e encaminhamento para a rede de serviços socioassistenciais, em grande defasagem no Município. Há interferências de políticos locais nas políticas públicas, pois, caso o usuário seja reconhecidamente um cidadão que apóia o prefeito, obterá benefícios via prefeitura. E, se a pessoa for considerada de oposição, terá seus direitos garantidos constitucionalmente suspensos e barrados pelos que obtém poder macropolítico, mecanismos binários de exclusão e de adesão à política social que deveria ser para todos. Essa é a realidade de Municípios pequenos, pois a dominação do controle do eleitorado nas mãos de coronéis conserva a população como sua clientela. Tal fato se reflete nas ações dos técnicos do CRAS que cotidianamente impedem as interferências políticas em suas atividades, sendo, muitas vezes, incompreendidos pela população que, frequentemente, não se beneficia com cestas básicas e pelos políticos que deixam de ganhar votos para a próxima eleição (Avelar \& Walter, 2008).

No que diz respeito à assistência social como norteadora das ações relacionadas ao CRAS, percebemos, no dia a dia do CRAS estudado, que sua política é colocada como hierarquicamente superior aos demais saberes e que possui retrocessos e avanços em sua história, denotando um território marcado por linhas duras historicamente construídas e mantidas. De sua criação, a assistência social era ação exclusiva do governo federal e associada à filantropia e à caridade. Somente com a mudança constitucional e com os movimentos sociais a assistência social foi regulamentada como uma política pública com participação de todas as esferas do governo e da sociedade civil (Ministério do Desenvolvimento Social e Combate à Fome, 2004; Ministério do Desenvolvimento Social e Combate à Fome, 2009). Desse percurso, notamos que, no cotidiano do CRAS estudado, as ações ora se manifestam como mantenedoras de ações assistencialistas, ora são responsáveis pela promoção de cidadania e do envolvimento dos sujeitos como protagonistas de suas vidas, um desafio tanto para o serviço social como para a Psicologia.

Quanto às ações dirigidas aos usuários, observamos que uma equipe multiprofissional, 
presente não só nos CRAS, deve se pautar na compreensão de que nenhuma especialidade sozinha será capaz de resolver todas as demandas de quem a procura, pois a realidade é multideterminada, processual e complexa. Para esse objetivo, percebemos a necessidade de as práticas se conectarem e refazerem seus campos em um objetivo maior: o do envolvimento dos usuários e o da devolução, aos usuários, do saber que Ihes foi destituído. Para isso, acreditamos ser necessário desenvolver a capacidade de a comunidade descobrir suas demandas, de se organizar de forma a que ela própria construa os dispositivos necessários para a melhoria de suas vidas. Nessa recuperação do saber comunitário, especialistas devem descobrir que "as massas não necessitam deles para saber" (Foucault, 1979, p. 71), e que, como iguais - usuários e especialistas -, devem se unir contra o poder opressor e em favor da potência reiventiva da vida.

Constatamos que ainda persiste, na equipe do CRAS, a noção de família presa ao modelo instituído e dominante - a família nuclear - diferentemente do que se apresenta na realidade. A família ideal, pais unidos em matrimônio e filhos decorrentes dessa união, ainda permanece como referencial para as intervenções do campo da Psicologia. Além disso, a família, ainda que seja o foco de ação dessa unidade, bem como dos profissionais que ali atuam, ao colocarem as dificuldades relacionadas a ela, o fazem culpabilizando-a, como é evidenciado também por Alberto et al. (2008).

Exatamente onde parece haver um problema - a família real, dentro de suas possibilidades econômicas, históricas, culturais e sociais - é que se deve considerá-la uma construção singular e circunstancial frente ao modelo mantido por setores conservadores de nossa sociedade, e não abordá-la de forma comparativa e desqualificativa, ou seja, a solução se encontra na construção do pensar e do como atuar a partir do vivido. A família deve, então, ser compreendida a partir de seus modos de agir habituais, pois é nesse cotidiano que se manifestam os caminhos a serem tomados como terrenos habitáveis, possíveis, e é essa compreensão que deve servir de base para as intervenções e os encaminhamentos da equipe (Centro Brasileiro para Infância e Adolescência, 1992).

Outro desafio percebido neste estudo diz respeito à necessidade de consolidação da articulação da rede socioassistencial, que, embora seja regulamentada pela política do CRAS e das políticas públicas em geral, ainda não se sustenta no cotidiano, mantendo a desarticulação dos trabalhos desenvolvidos nos diversos setores públicos. Para o desenvolvimento de ações continuadas e próximas das práticas da complexa realidade que encontramos, é preciso desenvolver a intersetorialidade, que pressupõe a articulação de setores sociais diversos, de saberes e de poderes para enfrentar os problemas da realidade social, o que significa dizer que, em vez de fragmentarmos os sujeitos e as intervenções, devemos então nos comprometer com ações de teoria e ações de prática que se multipliquem em uma única rede. "Assim estamos mais próximos de pensar as necessidades da comunidade de forma mais ampla e de agir nos problemas de forma menos pontual e considerando toda sua complexidade" (Wimmer \& Figueiredo, 2006, p. 152). Para a intersetorialidade acontecer, acreditamos que uma das possibilidades seja a de todos os profissionais envolvidos precisarem abandonar o glamour das ações e glórias individuais reforçadas pela condição pós-moderna, desafiando, portanto, os especialismos, as doutrinas dogmáticas e a hipervalorização do eu (Rolnik, 1997). A ousadia dessa nova forma de atuação é um 
processo que implica riscos "em função das resistências previsíveis de grupos de interesses" (Junqueira, 2004, p. 27).

Além disso, é preciso estar atento à tendência de patologizar e de achar que, em todas as queixas apresentadas, o sujeito carece de fazer terapia. Essa tendência em psicologizar é um percurso que os saberes psi- Psicologia, psiquiatria e psicanálise - têm percorrido desde suas fundações no Brasil. O surgimento da grande medicina no século XIX, que se desenvolveu como uma medicina clínica centrada em exames, em diagnósticos, na terapêutica individual e, principalmente, no "colóquio singular" (Foucault, 1979, p. 194), influenciou a construção de outros saberes, como a Psicologia. O modelo médico e a filantropia desencadearam uma série de novos agentes responsáveis pela disciplina e pela normalização no controle de todo o corpo social:

Tomemos o exemplo da filantropia no início do século XIX: pessoas que vêm se ocupar da vida dos outros, de sua saúde, da alimentação, da moradia... Mais tarde, dessa função confusa, saíram personagens, instituições, saberes... uma higiene pública, inspetores, assistentes sociais, psicólogos. (Foucault, 1979, p. 151)

Observamos, em nossa pesquisa, a necessidade de enquadrar, de classificar os usuários do serviço, e, em alguns momentos, tivemos a preocupação de que esses usuários não pudessem ser atendidos conforme a Psicologia tradicional.

Percebemos ainda, no cotidiano do CRAS estudado, não somente desafios e tensões mas também encontros produtivos e potencializadores. Os profissionais do CRAS revelam compreensão de sua empreitada e os territórios entre psicólogos e assistentes sociais também denotam zonas de fusão, de amizade e de trocas de experiências intensas. A respeito dos impactos do CRAS na comunidade estudada, psicólogos e assistentes sociais percebem que essa unidade cumpre com seus objetivos e promove, para os usuários, novos devires. Um dos assistentes sociais enfatizou que os projetos Fiando e desfiando a vida e Cantina da Cidadania possuem efeitos potencializadores de autonomia financeira, de promoção de saúde e de envolvimento dos usuários no recebimento da cesta básica. Por outro lado, os usuários contam suas experiências, e um deles relata que, do encontro com outros usuários e com os profissionais do CRAS, potencializou outros modos de subjetivação. A princípio, essa usuária relatou que psicólogo era médico para doido, e assistente social, aquele que se intromete na vida das pessoas. Ela não acreditava que o CRAS fosse um serviço continuado e duradouro. Sua história se confunde com a do CRAS, pois sua família foi a primeira a se cadastrar. Aos poucos, foi se aproximando dos profissionais, e suas desconfianças foram sendo desconstruídas. Ela chega à cidade em busca de melhores condições de trabalho, e, do seu encontro com o CRAS, consegue um lote na prefeitura e a comunidade se mobiliza para a compra de material e para a construção de sua casa. Seus filhos, antes sem registro de nascimento, agora possuem documentação e frequentam a escola local. Ela era obesa, e seus filhos desnutridos, e hoje controlam a alimentação na Cantina da cidadania. No tecer dos panos de prato, ela troca experiências de vida, sentimentos, enfrentamento do dia a dia e novas perspectivas de vir-a-ser.

Esse relato nos permite perceber um espaço fluido que percorre territórios rígidos e maleáveis. Em meio às tensões, vivenciamse encontros potencializadores de novos modos de ser dos usuários, psicólogos e assistentes sociais. Não se trata, portanto, de definirmos a verdade sobre as formas de intervenção e a execução das atividades que aqui se apresentaram, mas é somente, e apenas, uma tentativa de rastrearmos 
os territórios experimentados pelos atores dessa caminhada, territórios ora compostos pela dominância de segmentos, estratos, classificações, comparações e de horror ao diferente, ora compostos pela desterritorialização, pelos agenciamentos que se efetuam para trazer o novo, algo impensado, deixando que a potência da vida se atualize, de maneira alegre, nos encontros estabelecidos.

\section{Considerações finais}

O CRAS, como recente equipamento público, suscita que estudos sejam realizados sobre as práticas envolvidas nessas unidades espalhadas por todo o território nacional. A Psicologia, como outras profissões inseridas nas políticas públicas, foi então convocada a participar, trazendo diversas questões sobre seu campo de atuação, suas conexões com as demais profissões e, não menos importante, com suas implicações e com o impacto nos usuários.

Diante dessas colocações, o lugar da Psicologia no CRAS se apresenta como um espaço fluido e, portanto, em permanentes modificações. Sendo assim, só é possível defini-lo como espaço de encontros e de acontecimentos singulares.

Retomando a problemática da atuação do psicólogo, presenciamos hoje, no País, grandes discussões acerca da construção de outro modelo clínico que não seja somente o tradicional, com objetivos analíticos, diagnósticos e/ou curativos. De acordo com Ferreira Neto (2003), o conceito clínica social nasce historicamente como uma prática destinada ao segmento da camada pobre da população que ampliou o campo de atuação da Psicologia, antes desenvolvida hegemonicamente como atividade liberal e privada reservada às classes média e alta. Contudo, Romagnoli (2006) assinala que hoje a clínica social não se destina apenas às camadas mais baixas, mas configura uma resposta à multiplicidade que permeia todos os espaços onde os psicólogos estão inscritos. O que a torna uma prática emergente é a insistência em combater a massificação e a hegemonia de modelos que pretendem encapsular os sujeitos submetidos à globalização, ou seja, em não nos adaptarmos às exigências do mundo contemporâneo e em transformarmos nosso saber na arte da invenção, conectando-nos com outros territórios existenciais que escapam à psicologização e às patologias. Em qualquer ambiente que nós, psicólogos, estejamos, cabe perseguirmos as singularidades presentes nos encontros. Além disso, a clínica relacionada a um modo de escuta que possibilita a produção de diferenciação pode e deve estar presente em todos os campos de atuação da Psicologia. Isso implica uma atitude não totalizadora que desloca o enquadramento, os diagnósticos e as patologias para novas configurações de sentido, seja no consultório particular, seja nas práticas emergentes. A esse respeito, podemos afirmar que:

A psicoterapia não pode ser o modo por excelência da atuação profissional nem na atenção individual, nem no modelo do profissional liberal, o que significa que o psicólogo deve ocupar um espaço político e público, enfim, em que se possam compreender os processos de subjetivação tais como se produzem na sociedade brasileira e o diálogo com as referências teóricas conectadas a essa realidade (Alberto et al., 2008, p. 572) .

Nesse contexto, acreditamos que seja de nossa responsabilidade considerar não somente nos aspectos técnicos, mas, sobretudo, os efeitos éticos, políticos e sociais que qualquer saber acarreta. A Psicologia, assim, no nosso entender, pode tornar-se uma prática libertária capaz de habitar lugares ainda desconhecidos, de se inserir em novos campos de forma crítica e inventiva. 


\section{Laura Freire de Andrade}

Mestre em Psicologia pela Pontifícia Universidade Católica de Minas Gerais, Minas Gerais - BH - Brasil.

Roberta Carvalho Romagnoli

Doutora em Psicologia Clínica pela Pontifícia Universidade Católica de São Paulo, São Paulo - SP - Brasil.

E-mail para contato: robertaroma@uol.com.br

*Endereço para envio de correspondência:

Rua Mestre João Matias, no 178, Bairro Jardim Arizona, Sete Lagoas, Minas Gerais - BH - Brasil CEP 35700-396.

E-mail para contato: laurafreire.8@hotmail.com

Recebido 1/7/2009, 1a Reformulação 20/11/2009, 2e- Reformulação 14/12/2009, Aprovado 29/12/2009. 
Afonso, L. (2008). O que faz a psicologia no Sistema Único da Assistência Social? Jornal do Psicólogo, 25(91), 14.

Alberto, M. F. P., Almeida, D. R., Dória, L. C., Guedes, P. C., Sousa, T. R., \& França, W. L. P. (2008). O papel do psicólogo e das entidades junto a crianças e adolescentes em situação de risco. Psicologia: Ciência e Profissão, 28(3), 558-573.

Avelar, L., \& Walter, M. I. M. T. (2008). Lentas mudanças - o voto e a política tradicional. Opinião Pública, 14(1), 96 -122. Recuperado em 01 de outubro de 2008, da SciELO (Scientific Electronic Library Online): http://www.scielo.br/scielo/

Benevides de Barros, R. D. (2005). A psicologia e o Sistema Único de Saúde. Psicologia e Sociedade, 17(2), 21-25.
Birman, J. (2001). Mal-estar na atualidade: a psicanálise e as novas formas de subjetivação (3a ed.). Rio de Janeiro: Civilização Brasileira.

Borges, M. (2002). Os sonhos não envelhecem: histórias do clube da esquina (4a ed.). São Paulo: Geração Editorial.

Brasil. (1988). Constituição da República Federativa do Brasil. Brasília, DF: Autor.

Centro Brasileiro para a Infância e Adolescência. (1992). Cadernos de Ação: trabalhando com famílias. São Paulo: Autor.

Conselho Federal de Psicologia. (2006). Jornal do Conselho Federal de Psicologia. Brasília, DF: Autor. 
Conselho Regional de Psicologia de Minas Gerais. (2007). Jornal do Psicólogo. Belo Horizonte: Autor.

Deleuze, G., \& Guattari, F. (1996). Micropolítica e segmentaridade. In G. Deleuze, \& F. Guattari, Mil platôs: capitalismo e esquizofrenia (A. L. Oliveira, trad., pp. 83 -115). Rio de Janeiro: Ed. 34.

Demo, P. (1995). Cidadania tutelada, cidadania assistida. Campinas, SP: Autores Associados.

Demo, P. (1996). Política social, educação e cidadania (2a ed.). Campinas, SP: Papirus.

Ferreira Neto, J. L. (2003). Qual é o social da clínica? Uma problematização. Pulsional: Revista de Psicanálise, 167(3), 57-65.

Ferreira Neto, J. L. (2004). A formação do psicólogo: clínica, social e mercado. São Paulo: Escuta.

Foucault, M. (1979). Microfísica do poder (24a ed.). Rio de Janeiro: Graal.

Guerra, A. M. C. (2002). O social na clínica e a clínica do social: sutilezas de uma prática. In B. D. Gonçalves, A. M. C. Guerra \& Moreira, J. O. (Orgs.), Clínica e inclusão social: novos arranjos subjetivos e novas formas de intervenção (pp. 29-48). Belo Horizonte: Campo Social.

Hüning, S. M., \& Guareschi, N. M. F. (2005). O que estamos construindo: especialidades ou especialismos? Psicologia \& Sociedade, 17(1), 89-92.

Instituto Brasileiro de Geografia e Estatística. (2000). Censo 2000. Recuperado em 21 de março de 2008, de http:// www.ibge. gov.br/ cidadesat/default.php.

Junqueira, L. A. P. (2004). A gestão intersetorial das políticas sociais e o terceiro setor. Saúde e Sociedade, 13(1), 25-36.

Kirst, P. G., Giacomel, A. E., Ribeiro, C. J. S., Costa, L. A., \& Andreoli, G. S. (2003). Conhecimento e cartografia: tempestade de possíveis. In T. M. G. Fonseca \& P. G. Kirst (Orgs.), Cartografias e devires: a construção do presente (pp. 91-101). Porto Alegre: Ed. da UFRGS

Maciel Junior, A., Kupermann, D., \& Tedesco, S. (Eds.). (2005). Polifonias: clínica, política e criação. Rio de Janeiro: Contra Capa.

Mairesse, D. (2003). Cartografia: do método à arte de fazer pesquisa. In T. M. G. Fonseca \& P. G. Kirst (Eds.), Cartografias e devires: a construção do presente (pp. 259-271). Porto Alegre: Ed. da UFRGS.

Ministério do Desenvolvimento Social e Combate à Fome. (2004). Política Nacional de Assistência Social. Brasília, DF: Autor.
Ministério do Desenvolvimento Social e Combate à Fome. (2006). Proteção Básica do Sistema Único da Assistência Social: Orientações Técnicas para o Centro de Referência da Assistência Social. Versão Preliminar. Brasília, DF: Autor.

Ministério do Desenvolvimento Social e Combate à Fome. (2009). A história da assistência social brasileira. Brasília, DF: Autor. Recuperado em 23 janeiro, acesso MDS (Ministério do Desenvolvimento Social e Combate à Fome): http://www. mds.gov.br/suas/conheca/conheca09.asp.

Passos, E., \& Benevides de Barros, R. (2004). Clínica, política e as modulações do capitalismo. Lugar Comum, (19-20), 159-171.

Pelbart, P. P. (2000). Subjetividade esquizo. In P. P. Pelbart, $A$ vertigem por um fio: políticas da subjetividade contemporânea (pp. 161-182). São Paulo: Iluminuras.

Rolnik, S. (1997). Uma insólita viagem à subjetividade, fronteiras com a ética e a cultura. In D. Lins (Ed.), Cultura e subjetividade: saberes nômades (pp. 25-34). Campinas, SP: Papirus.

Romagnoli, R. C. (2004). O sintoma da família: excesso, sofrimento e defesa. Interações, 9(18), 41-60.

Romagnoli, R. C. (2005). Famílias na rede de saúde mental e esquizoanálise: uma aproximação possível. In T. FéresCarneiro, Família e casal: efeitos da contemporaneidade (pp. 251-265). Rio de Janeiro: Ed. da PUC - Rio.

Romagnoli, R. C. (2006). Algumas reflexões acerca da clínica social. Revista do Departamento de Psicologia da UFF, 18(2), 47-56.

Romagnoli, R. C., Moreira, J. O., \& Neves, E. O. (2007). O surgimento da clínica psicológica: da prática curativa aos dispositivos de promoção da saúde. Psicologia: Ciência e Profissão, 27(4), 608-621.

Schérer, R. (2005). Sem rosto: limites das prerrogativas do eu (moi) na criação - a idéia de mínimo em Deleuze. In A. Maciel Junior, D. Kupermann \& S. Tedesco (Orgs.), Polifonias: clínica, política e criação (pp. 131-139). Rio de Janeiro: Contra Capa.

Wimmer, G. F., \& Figueiredo, G. O. (2006). Ação coletiva para qualidade de vida: autonomia, transdisciplinaridade e intersetorialidade. Ciência \& Saúde Coletiva, 11(1), 145-154. 